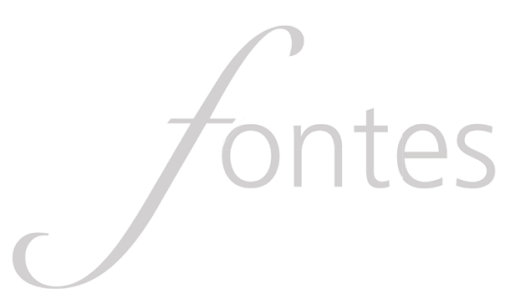

\title{
Tras las huellas de la Inquisición del Río de la Plata y el Tucumán por bibliotecas de y museos de Córdoba (Argentina)
}

Searching the Footprints of the Inquisition of the Río de la Plata and Tucumán in the Museums and libraries of Córdoba (Argentina)

\section{Jaqueline Vassallo}

Universidad Nacional de Córdoba, Facultad de Filosofía y Humanidades, Córdoba, Argentina.

Investigadora independiente del Consejo Nacional de Investigaciones Científicas y Técnicas (CONICET), Argentina.

jaquelinevassallo@yahoo.es

(D) https://orcid.org/0000-0003-1995-9476
RESUMEN: El trabajar tomando como eje central las actuaciones de las comisarías que operaron en la periferia del imperio español, nos ha permitido evidenciar las marcas producidas en fuentes que no se hallan en los archivos que formó cada tribunal. Se hizo necesario ahondar en las redes que tejieron los comisarios con las autoridades locales o las obligaciones que debían cumplir siguiendo las órdenes de los superiores para poder hallar nuevas evidencias documentales en dos bibliotecas y un museo de la ciudad de Córdoba (Argentina).

PALABRAS CLAVE: Inquisición; documentos; Córdoba; bibliotecas; museos ABSTRACT: Working on the records of the inquisitorial comisarias of the Spanish Empire's periphery revealed evidences in sources that cannot be found in the tribunal's own archives. Thus, it was necessary to investigate the networks build between comisarios and local authorities, and the obligations that the orders sent by the higher authorities produced on such officials. This allowed us to find new documents and evidences in two libraries and one museum of the Argentinian city of Córdoba, which hosted a comisaría dependent of Lima's tribunal for more than two centuries.

KEYWORDS: Inquisition; documents; Córdoba; libraries; museums

\section{A manera de presentación}

A lo largo de más de tres siglos de funcionamiento la Inquisición española - y sus distintas versiones trasplantadas en otros países europeos y americanos -, produjeron una enorme 
cantidad de documentos ${ }^{1}$. Desde sus inicios, la institución instrumentó políticas archivísticas y le dio un rol central a la organización y conservación de los documentos, para acceder a la información que ellos contenían.

Con el devenir de las primeras actuaciones, y la singularidad de las mismas - en las que se privilegiaba el absoluto secreto -, el archivo se erigió como un elemento imprescindible para el funcionamiento de la institución. Recordemos que el archivo fue uno de los medios utilizados por la monarquía para llevar adelante su política de guarda y conservación del registro en archivos reales. Primero el Consejo y luego cada tribunal, debía tener un archivo propio, que se alimentaba de las múltiples tipos documentales que se producían².

La suerte que corrieron cada uno de estos acervos luego de la supresión de la institución se inscribe en el marco de las guerras libradas en la península, los sucesivos intentos de supresión o las guerras de independencia que se llevaron adelante en América Latina. Luego, dicha suerte quedó definitivamente ligada a las políticas archivísticas que llevaron adelante Perú, México y Colombia en relación a la organización de sus archivos estatales o al rol que jugó la iglesia a la hora de conservar estos documentos que consideró como propios. Incluso también quedaron condicionados por conflictos posteriores que tuvieron lugar, como la Guerra del Pacífico, en la que estuvieron involucrados los países de Chile y Perú.

La preocupación por la existencia, individualización y acceso a fondos documentales vinculados a la Inquisición española fue un asunto de especial interés para Joaquín Pérez Villanueva y Bartolomé Escandell Bonet, los directores de la obra Historia de la Inquisición en España y América, publicada en los años 80 del siglo pasado. Ellos pusieron la cuestión en el centro del debate a través de los aportes de Pinto Crespo, Pérez Ramírez, Avilés Fernández y Ballesteros Gaibrois ${ }^{3}$.

Estos autores estaban interesados en ofrecer una suerte de mapeo de la documentación que se halla albergada en los archivos estatales nacionales españoles: el Archivo Histórico Nacional de Madrid, el Archivo General de Simancas, el Archivo de Indias,

1. Trabajo realizado en el marco de Proyecto I+D+i HAR HAR2014-52434-C5-3-P. "Vida cotidiana, cultura gráfica y reforma católica en el mundo hispánico: tolerancias, resistencias y censuras", dirigido por Manuel Peña Díaz (UCO), MIMECO, España. Para la realización de este trabajo agradezco el asesoramiento desinteresado y generoso de la Lic. en Archivología Noelia García y de la Museóloga Guadalupe Biscayart Melo, quienes me abrieron las puertas de las instituciones donde trabajan y orientaron en la búsqueda de documentos que están vinculados a la Inquisición local.

2. Virgilio Pinto Crespo. "La documentación Inquisitorial”. In: La Inquisición. Madrid: Ministerio de Cultura, 1982, pp. 93-106.

3. Virgilio Pinto Crespo, Dimas Pérez Ramírez, Miguel Avilés Fernández y Manuel Ballesteros Gaibrois. “Fuentes y Técnicas del Conocimiento Histórico del santo Oficio". In: J Pérez Villanueva y B. Escandell Bonet (dir.). Historia de la Inquisición en España y América, tomo 1. Madrid: Biblioteca de Autores Cristianos y Centro de Estudios Inquisitoriales, 1984, pp. 58-105. 
el Archivo Diocesano de Cuenca, el Archivo de la Real Audiencia de Zaragoza, el Archivo del Museo Canario, el Archivo de la Real Corona de Aragón de Barcelona y Cataluña; así como en la Biblioteca Nacional de Madrid y en los Archivos nacionales de México y Lima, siguiendo las lógicas de organización de los archivos inquisitoriales; es decir, un archivo por tribunal, pero siempre teniendo en cuenta la dispersión que sufrieron los fondos por distintos motivos. También hicieron gestiones para averiguar por el paradero del archivo del tribunal de Cartagena de Indias, los documentos que existen en la Biblioteca Nacional de Chile- específicamente los manuscritos de José Toribio Medina-, y la documentación existente en Guatemala vinculada al tribunal mexicano ${ }^{4}$.

También se ofrecía información sobre los documentos que se habían desmembrado de su orden original, sobre la Inquisición española y que aún hoy se hallan en la Biblioteca Real de Copenhague, el British Museum o en la Biblioteca Nacional de París, entre muchas otras unidades de información europeas y norteamericanas ${ }^{5}$.

Como bien señaló Avilés Fernández, desde la perspectiva de la ciencia archivística, los archivos inquisitoriales son "archivos muertos", como consecuencia de la extinción de la institución productora. Mientras la Inquisición estuvo "viva”, sus fondos “nacieron, crecieron y se multiplicaron, reproduciendo en su propio ser y en su propia distribución las características funcionales del aparato que los produjo" 6 .

En las conclusiones de su trabajo, Ballesteros Gaibrois reclamaba a los archiveros "una sistemática catalogación de los fondos" y publicación de los mismos ${ }^{7}$. Recordemos que los trabajos se escribieron y publicaron a mediados de los años 80, cuando internet no estaba al alcance de los investigadores ni existían auxiliares descriptivos puestos en línea.

Sin embargo, más allá de lo explorado por estos autores, no llegaron a evidenciar ene se momento que la Inquisición dejaba huellas en otros tipos documentales que no quedaron resguardados en los archivos de cada tribunal e incluso en el del Consejo. Las actuaciones de los comisarios, de los familiares, así como de las redes institucionales que tejieron con otros funcionarios reales - aún cuando no podía quedar ninguna copia de lo tramitado -, quedaron plasmadas en diversos documentos tales como actas capitulares, libros de visita de cárcel, actas de expurgo realizadas en textos de libros. Muchos de estos documentos se encuentran en archivos municipales e incluso museos y bibliotecas universitarias de diversos países. Tampoco debemos dejar de mencionar a coleccionistas

\footnotetext{
4. Idem, pp. 90-103.

5. Idem, pp. 83-90.

6. Idem, pp. 83-89.

7. Idem, p. 91.
} 
que accedieron a la tenencia de esta documentación y que en muchos casos fue donada a alguna institución pública.

El trabajar tomando como eje central las actuaciones de las comisarías que operaron en la periferia del imperio español, nos ha permitido evidenciar las marcas producidas en otros tipos documentales que no se hallan necesariamente en los archivos que formó cada tribunal, sobre todo el del tribunal de Lima, cuyos documentos se hallan dispersos en unidades de información de España, Perú y Chile. Por lo tanto, ha sido un desafío encontrar documentos vinculados a las actuaciones inquisitoriales en el actual territorio argentino, donde según hemos podido comprobar existieron comisarías en Córdoba, Buenos Aires, Santiago del Estero, Santa Fe, Mendoza, Corrientes, la Rioja y Catamarca. El salir de la consulta en unidades de información "habituales" para buscar rastros y marcas nos llevó a encontrar documentos que se hallan en bibliotecas y un museo de la ciudad de Córdoba (Argentina), donde funcionó una comisaría, dependiente del tribunal de Lima durante más de dos siglos.

\section{La construcción del pasado colonial de Córdoba a través de archivos y museos}

Córdoba es una ciudad que por su historia cuenta con gran cantidad de archivos, museos y centros de documentación estatales y privados. Fundada en 1573, por el andaluz Cerónimo Luis de Cabrera, pronto se transformó en una de las ciudades más importantes del sur del virreinato peruano, y luego del virreinato del Río de la Plata. Fue cuna de la primera universidad de la región - fundada por los jesuitas a principios del siglo XVII-, sede del obispado, centro cultural, comercial y religioso donde se asentaron numerosas órdenes religiosas, y los dos primeros conventos femeninos de la actual Argentina. Por su ubicación estratégica constituía cruce de caminos entre Buenos Aires y Chile, como asimismo, paso obligado para partir hacia el Alto Perú.

Las actuaciones de la comisaría de Córdoba que trabajó bajo la dependencia del tribunal de Lima desde principios el siglo XVII hasta 1813, quedaron conservadas en tres legajos que se hallan en el Archivo del Arzobispado de Córdoba, Sección Inquisición. El fondo posee fundamentalmente denuncias que conformaban las "cabezas del proceso", cartas, autos, notas edictos e inventarios. Asimismo, hallamos documentación que evidencian comunicación frecuente entre los comisarios y el tribunal limeño: cartas, notas, certificaciones, acuso de recibo de documentos, respuestas de consultas recibidas, nombramientos, pedidos de información, edictos de "fe y anatemas" e instrucciones para interrogar, entre otros. El estado de conservación es sumamente aceptable, aún cuando no se hallen debidamente catalogados (salvo el tomo III que comprende los años 1711-1827). 
Las fojas aún se conservan sueltas ${ }^{8}$, como se ordenaba en las Instrucciones para comisarios, y tampoco presentan foliatura original.

Como señaló Aurelio Tanodi hace ya medio siglo, Córdoba fue la ciudad- después de Buenos Aires-, que ha conservado más amplias series documentales desde la época colonial, que cualquier otra ciudad argentina. Sus repositorios "son un verdadero orgullo de la ciudad, que por su tradición cultural ha merecido el título de Córdoba "la Docta”. Una ciudad que ha construido parte de su identidad vinculada a un "ilustre" pasado colonial y que puede probar mediante la existencia de numerosas iglesias, museos y de una universidad que cuenta con más de 400 años.

No es casual, entonces, que en Córdoba existieran tempranas políticas de promoción de la escritura del pasado, entre ellos, la organización de archivos públicos y de instituciones académicas oficiales que produjeran trabajos históricos. Fue así como se creó el Instituto de Estudios Americanistas (1936), por Ordenanza del H. C. S de la Universidad, para la promoción de investigaciones históricas, paleográficas, archivísticas, etc. En 1941 el Instituto se desmembró para formar parte del Instituto de Arqueología, Lingüística y Folklore, luego Instituto de Antropología. Ese mismo año, se creó el Archivo Histórico de la Provincia de Córdoba y la Junta Provincial de Historia de Córdoba. Posteriormente, se fundó el Archivo Histórico Municipal (1970), la Escuela de Bibliotecarios y Archiveros (1958 y 1960), el Departamento de Historia (1947 y 1957) y la Escuela de Historia (1968).

Tampoco podemos dejar de mencionar la presencia del Archivo Arquidiocesano que resguarda documentos que datan de la época de funcionamiento de la diócesis del Tucumán. Desde 1699 Córdoba fue sede de la diócesis del Tucumán y a partir de 1807, sede del obispado que comprendía la jurisdicción de La Rioja, San Juan, San Luis y Mendoza. Dicho obispado fue elevado a Arquidiócesis en 1934 cuya jurisdicción comprendía el territorio de la provincia de Córdoba ${ }^{10}$.

Una fuerte presencia de la Iglesia en la ciudad- que data de tiempos coloniales-, que tuvo fuertes incidencias en la vida social y cultural, aportó una temprana escritura de la historia local surgida de la pluma de sacerdotes; algunos de ellos, vinculados a la Universidad Nacional de Córdoba, como fue el caso de Monseñor Pablo Cabrera (18571936). Estos sacerdotes, entre quienes también encontramos al jesuita Pedro Grenón (1878-

8. Nelson Dellaferrera. "Apuntes para la Historia de la Audiencia Episcopal del Tucumán (1688-1888)". Revista de Historia del Derecho, 21 (1993), pp. 97-131.

9. Aurelio Tanodi. Guía de los Archivos de Córdoba. Córdoba: Dirección General de Publicaciones de la Universidad Nacional de Córdoba, 1968, p. XXIV.

10. Idem, p. 108. 
1973), tuvieron acceso a la documentación que se hallaba en archivos estatales o eclesiásticos, cuando aún no estaban debidamente organizados ni se permitía el acceso a investigadores. Incluso, se les facilitó la apropiación y tenencia de documentos para la realización de sus trabajos, lo que derivó en la formación de colecciones documentales propias.

Ellos escribieron una historia oficial de la Iglesia o le dieron una impronta eclesiástica a los temas que trabajaban, apegados a las fuentes archivísticas con las que trabajaban. Incluso, Grenón, se dedicó a publicar documentos que había hallado en los archivos locales, siguiendo de cerca los postulados metodológicos de los historiadores decimonónicos. Pero ninguno de ellos aludió a la Inquisición en Córdoba, fue muchos años más tarde cuando el historiador y divulgador de la historia local, Efraín Bischoff, publicó por primera vez el fascículo La Inquisición en Córdoba, en 1992¹.

Según hemos constatado en el Archivo del Arzobispado de Córdoba, la comisaría actuó no solo recibiendo denuncias o deteniendo personas, sino que también realizó inspecciones de bibliotecas institucionales y particulares, incluso, expurgos. En una ciudad universitaria, había muchas bibliotecas: la de Universidad, la de numerosas órdenes religiosas, la del obispo, así como otras tantas que estaban en manos de particulares. Asimismo, durante el último cuatro del siglo XVIII, los comisarios detuvieron a personas sospechadas de cometer "delitos contra la fe" en la Real Cárcel del Cabildo, donde también se alojaban los detenidos por la justicia ordinaria.

Fue así como, al ir tras las huellas de estas actividades, nos encontramos con registros documentales vinculados a la comisaría local tanto en el Museo Histórico de la Universidad Nacional de Córdoba, donde se aloja la "Colección jesuítica”, es decir, la que fue la "librería grande" de la Universidad jesuítica; como también en la Biblioteca del Tribunal Superior de Justicia de Córdoba. Se trata de unidades de información donde habitualmente no se encuentran documentos, ni colecciones documentales, sino bibliográficas. También hemos hallado documentos vinculados a la Inquisición, que tenía Monseñor Pablo Cabrera, en su colección privada y que en la actualidad se halla en la Biblioteca de la Facultad de Filosofía y Humanidades de la Universidad Nacional de Córdoba.

11. Efraín Bischoff. La Inquisición en Córdoba. Córdoba: Junta Provincial de la Historia de Córdoba, 1992. 


\section{Tras nuevas huellas documentales de la Inquisición cordobesa}

La Universidad jesuítica de Córdoba tenía una de las bibliotecas más grandes de la región. Recordemos que esta universidad fue la única que funcionó en la actual Argentina durante tiempos coloniales. Sus orígenes están ligados a la gestión de la Compañía de Jesús, que primero fundó el Colegio Máximo y luego se transformó en Universidad particular (1621). Durante un siglo y medio- de 1614 a 1767-, los jesuitas regentearon la Universidad con sus dos facultades (Artes y Teología) como una institución independiente del poder real. Esta regencia terminó en julio de 1767, cuando el comisionado Fernando Fabro, comunicó la real orden de Carlos III que dispuso la expulsión de la Compañía de todos los territorios españoles ${ }^{12}$.

Como sabemos, la Compañía ubicó al libro como el centro de toda su actividad pedagógica y pastoral. Cuidó que sus instituciones mantuvieran una continua actualización de sus bibliotecas, que se encontraban debidamente organizadas y hasta contaron con una clasificación bibliográfica propia. La biblioteca de la Universidad había nacido con la fundación de la institución y fue creciendo del aporte de libros que hacían los jesuitas que llegaban de Europa, así como de donaciones de particulares como la efectuada por el obispo Trejo y Sanabria o la de Ignacio Duarte y Quirós, quien también se desempeñó como comisario de la Inquisición durante el siglo XVII' ${ }^{13}$.

La biblioteca, como tantas otras, debió pasar por la censura inquisitorial e incluso, sus libros debieron ser expurgados. Sin embargo, cabe recordar como señala Manuel Peña Díaz, que la censura "no fue un muro divisorio entre lo permitido y lo prohibido, sino un territorio donde lo herético y lo ortodoxo se tocaban, donde lo público y lo privado se confundían, donde el discurso religioso acusador y amenazante penetraba y violaba conciencias"14. Córdoba era una ciudad universitaria que favorecía la circulación de textos, que atraía al libro y por lo tanto, las recomendaciones que recibieron los comisarios desde Lima de "extremar los controles" y "recibir denuncias" fueron frecuentes ${ }^{15}$; sin embargo, las inspecciones a las bibliotecas y los expurgos que se realizaron no escaparon a las tensiones y contrastes que señala el autor andaluz en Escribiry prohibir.

12. Celina Lértora Mendoza "La enseñanza elemental y universitaria". In: Nueva Historia de la nación Argentina, tomo III. Buenos Aires: Planeta, 1999, pp. 369-402.

13. Silvano Benito Moya "Bibliotecas y libros en la cultura universitaria de Córdoba durante los siglos XVII y XVIII". Información, cultura y sociedad, 26 (ene-jun. 2012), pp. 13-39. Recuperado en 07 de octubre de 2018, de http://www.scielo.org.ar/scielo.php?script=sci_arttext\&pid=S1851-17402012000100002\&lng=es\&tlng=en

14. Manuel Peña Díaz. Escribir y prohibir. Inquisición y censura en los Siglos de Oro. Madrid: Cátedra, 2016, p. 17.

15. Esteban Llamosas. La literatura jurídica de Córdoba del Tucumán en el siglo XVIII. Córdoba: Lerner editora, 2008 , p. 346. 
Hoy podemos acceder al registro documental del expurgo que se realizó en el libro de Baltasar Paes, Commentarii in epistolam beati lacobi apostoli, el 17 de octubre de 1712, por el comisario Francisco de Vilchez Montoya y Tejeda ${ }^{16}$. Por ese entonces, eran los mismos comisarios los que tenían la tarea concreta de visitar las bibliotecas, recoger los libros prohibidos y ejecutar las expurgaciones correspondientes ${ }^{17}$.

Este libro formó parte de la "librería grande" de la Universidad jesuítica, que actualmente se encuentra albergada en el Museo Histórico de la Universidad Nacional de Córdoba, ubicado en la sede el antiguo rectorado de la calle Obispo Trejo 242, y forma parte de la Manzana Jesuítica que fue declarada Patrimonio de la Humanidad por la UNESCO, en el año 2000.

Se trata de una colección conformada por 1602 títulos y alrededor de 2500 volúmenes, situados en las salas de la planta baja del citado museo, luego de que fueran restituidos por orden del decreto presidencial del año 2000, de la Biblioteca Nacional de Buenos Aires. Hasta allí habían llegado en 1811, luego de varios avatares que sufrió la biblioteca tras la expulsión de la orden, en 1767.

La biblioteca, que a fines el siglo XVIII Ilegó a contar con 3200 títulos registrados en el Index Librorum Bibliothecae Collegii Maxii Cordubensis Societatis, fue trasladada de inmediato al convento de los franciscanos, por orden de la Junta de Temporalidades. Y esto no es casual, ya que a partir de entonces los franciscanos se hicieron cargo de la Universidad hasta 1808.

Luego de producida la revolución de mayo de 1810, la Junta dispuso que una buena parte de los libros fueran trasladados a Buenos Aires para fundar la Biblioteca Nacional. Y el resto, fue destinado a conformar la Biblioteca Mayor de la Universidad, que abrió sus puertas en 1818.

La Colección concentra una importante cantidad de textos de temática variada dentro de los saberes propios de los siglos XVII y XVIII: teología, filosofía, hagiografías, diccionarios, medicina, astronomía, matemáticas, física, historia natural, geografía, arquitectura, música y obras de literatura clásica ${ }^{18}$.

En otro orden, cabe agregar que la Universidad franciscana empezó a formar los primeros abogados del Virreinato del Río de la Plata a partir de 1791. Incluso, dos de sus

\footnotetext{
16. Colección Jesuítica, Museo Histórico de la Universidad Nacional de Córdoba.

17. Esteban Llamosas, La literatura jurídica, op. cit., p. 347.

18. Celeste Maldonado y María Ángela Giorgetti. “Descripción bibliográfica de 'La Colección Jesuítica' de Biblioteca Mayor (siglos XVI-XVIII)". Ponencia consultada el 7 de octubre de 2018 en: https://www.bn.gov.ar/resources/conferences/pdfs/ponencia_giorgetti_maldonado.pdf
} 
profesores, como Victorino Rodríguez o José Conzález, también ejercieron la función de justicia como alcaldes del cabildo. Las causas judiciales producidas por la justicia colonial estuvieron en el Archivo de Tribunales hasta que a mediados del siglo XX fueron derivadas al Archivo Histórico de la Provincia, donde hoy pueden ser consultadas. Mientras que los libros de visita de cárcel se guardaron en Oficialía Mayor del Palacio Municipal 6 de Julio (Municipalidad de Córdoba) y no en el Archivo Histórico Municipal como debiera correspondido hacerlo.

Sin embargo, hemos hallado en forma casual en febrero de 1996, un libro de visita de cárcel perdido, correspondiente a los años 1789-1795 en la Biblioteca del Tribunal Superior de Justicia de la Provincia de Córdoba. Se trata de una de las seis bibliotecas que dispone el Poder judicial de la ciudad y la más antigua, fundada en 1925 por el Dr. Enrique Martínez Paz. El libro manuscrito, se hallaba en una vitrina junto a varios libros antiguos tales como las Partidas de Alfonso X y las Leyes de Toro. Se encontraba en un sector de la biblioteca que no es utilizada a diario por abogadas y abogados que acudían a esta unidad en busca de información vinculada al ejercicio profesional actual (normas, jurisprudencia y doctrina).

Cabe agregar que la directora de la biblioteca ignoraba la existencia del libro y cómo había llegado hasta ese lugar.

Las actas que componen este libro tienen un valor singular ya que se trata de los años en que gobernó en Córdoba del Tucumán el primer gobernador intendente, Marqués de Sobremonte que implementó fuertes políticas de control social represivas que las actas reflejan en la gran cantidad de personas procesadas, pero también detenidas temporalmente en la cárcel del cabildo ${ }^{19}$.

Entre los listados que mes a mes se confeccionaban con motivo de la visita que formalizaban las autoridades judiciales los días sábados, hemos hallado personas detenidas por la Inquisición local que compartían la celda con otros que estaban sometidos a instancias jurisdiccionales y represivas diferentes. No olvidemos que si bien era el lugar en el que los acusados por la justicia ordinaria debían esperar el dictado de la sentencia mientras se substanciaba el proceso penal, la práctica había mezclado considerablemente sus funciones ya que también se la utilizó para encerrar a "locos" sin familia, sentenciados a los que no se les podía enviar a destino por falta de recursos para el traslado o esposas, hijas, hijos y esclavos que se hallaban alli por orden de los maridos, padres o amos cuando

19. Jaqueline Vassallo. Mujeres delincuentes. Una mirada de género en la Córdoba del siglo XVIII. Córdoba: Centro de Estudios Avanzados, 2006, pp. 161-175. 
no se habían ajustado al cumplimiento de los roles asignados en el marco de una sociedad tradicional, jerárquica y patriarcal ${ }^{20}$.

Como podemos observar, los perseguidos por la comisaría de Córdoba- que en teoría debían ser trasladados a Lima-, estuvieron lejos de estar alojados en soledad, como lo disponía la Inquisición.

El acta de la visita de cárcel que tuvo lugar el 26 de setiembre de 1789- cuyo texto completo se acompaña como anexo documental de este artículo-, es sólo un ejemplo de lo que ocurrió con Mariano Brito, quien fue detenido por orden de la Inquisición local y allí estuvo entre setiembre de 1789 y el mes de julio de 1790, hasta que en la visita que se produjo el 31 de julio de 1790, ya no apareció mencionado 21 . Lamentablemente no disponemos más información sobre el caso: no hemos encontrado las imputaciones que le pudo hacer el comisario, quien lo mantuvo detenido por un largo tiempo, ni su destino final, pero sí sabemos que no se le sustanció una causa en Lima.

Por su parte, la colección particular de Monseñor Pablo Cabrera también contiene documentos vinculados a la Inquisición que aún no han sido trabajados por la historiografía local. Pablo Cabrera (1857-1936) fue un sacerdote-historiador de Córdoba que tuvo relevancia como intelectual multifacético, de prestigio a nivel nacional e internacional, a principios del siglo XX. Durante varias décadas combinó su trabajo pastoral con el de historiador, pero a partir de 1897 se dedicó con exclusividad a la disciplina histórica y dentro de la cual ganó gran reputación entre historiadores, etnólogos, arqueólogos y lingüistas. Fue miembro del Ateneo de Córdoba (1894), de la Academia Nacional de Ciencias (1915), y Director del Museo Histórico Provincial (1919). Además, en 1924 fundó la Junta de Estudios Históricos que en 1928 se transformó en Junta de Historia y Numismática Americana. En el ámbito nacional fue designado socio activo de la Sociedad Científica Argentina (1934) y en el internacional fue miembro de la prestigiosa Sociedad de Americanistas de París (1927). También fue un prolífico autor de libros y artículos publicados en la Revista de la Universidad y el diario clerical Los Principios. Publicó alrededor de cincuenta monografías, entre las que se encuentran por ejemplo: El primitivo obispado de Tucumán y la iglesia de Salta (1906); Ensayos sobre etnología argentina. Los lules (1910); Córdoba de la Nueva Andalucía. Noticias etnográficas e históricas acerca de su fundación (1917), Cultura y

20. En este punto, resulta imprescindible aclarar que a la par de esta cárcel oficial, también existieron en la jurisdicción pese a la reglamentación en contrario - cárceles privadas que tenían autoridades civiles, eclesiásticas y también, particulares. 21. Biblioteca del Tribunal Superior de Justicia. Libro de Visita de Cárcel. Años 1789-1795. 
beneficencia durante la colonia, obra que consta de dos tomos $(1925,1926)^{22}$. Es decir, temas vinculados al pasado colonial de Córdoba y “teñidos de una visión eclesial que nunca negó ni disminuyó", ya que Cabrera "siempre recordó con beneplácito su lugar como miembro de la Iglesia Católica"23.

En 1936, luego de su fallecimiento, la colección documental, biblioteca, museo privado y archivo personal fueron una parte vendidos y otra donada por la familia a la Universidad Nacional de Córdoba. De inmediato, documentos, objetos y muebles fueron destinados al Instituto de Estudios Americanistas (IEA). El Instituto funcionó hasta la década del 80 del siglo pasado y en 1999, la Biblioteca del Ex Instituto se integró como Sección especializada a la Biblioteca Central de la Facultad de Filosofía y Humanidades, situada en el Pabellón Tosco de la Ciudad Universitaria.

La colección documental fue reunida por Cabrera a lo largo de su vida entre fines del siglo XIX y principios el XX. La proveniencia archivística es diversa: repositorios del Arzobispado de Córdoba, fondos conservados en el Archivo de Tribunales de Córdoba y en el de la Universidad, archivos eclesiásticos de la diócesis local y de familias tradicionales cordobesas que le confiaron al sacerdote la custodia de sus documentos personales. Estamos hablando de 13.270 documentos, manuscritos e impresos producidos entre los años 1539 y $1936^{24}$.

Es una colección artificial, es decir, está conformada por piezas documentales aisladas de origen público o privado, desgajadas intencionalmente por el coleccionista de la organicidad original en que fueron producidas. Se trata mayormente de documentos sueltos, ordenados numéricamente, guardados en cajas algunos y otros encuadernados y el orden no corresponde a ninguna clasificación por materias ni cronológica, sino al tiempo de adquisición y a los temas que estudiaba Cabrera ${ }^{25}$.

No es causal, entonces, que los documentos vinculados a la Inquisición aparezcan de ese modo, sueltos, sin organicidad, como extraídos de otros cuerpos. Tal vez, pueden provenir de los tres legajos que componen el fondo documental de la Comisaría cordobesa.

22. Graciela del Valle Costilla, Silvia Fois, Noelia García, Clelia Gutiérrez y Sandra Pérez. "Acciones para la preservación y difusión del patrimonio histórico. Notas sobre la digitalización de la 'Colección Documental Monseñor Pablo Cabrera' FFyHUNC". In: Aportes para pensar la Archivología en el siglo XXI, desde la investigación, la extensión y la práctica. Córdoba: Editorial de la Facultad de Filosofía y Humanidades, 2014, pp. 33-40.

23. Denise Reyna Berrotarán “Doctor Honoris Causa a Monseñor Pablo Cabrera: las líneas historiográficas de un homenaje”. Coordenadas. Revista de Historia Local y Regional. Año III, vol. 2 (2015). Consultada el 7 de septiembre de 2018 en https://rdu-demo.unc.edu.ar/bitstream/handle/123456789/944/MonsenorPabloCabrera.pdf?sequence=1https://rdu-

24. Graciela del Valle Costilla, Silvia Fois, Noelia García, Clelia Gutiérrez y Sandra Pérez, op. cit., p. 34.

25. Idem. 
A saber: varios edictos de fe y anatemas relativos a libros prohibidos, escritos e imágenes satíricas que enviaba la Inquisición de Lima $(1788,1772)$. También una sumaria iniciada por Miguel Medina, el capellán y teniente cura de Villa de la Carlota, situada en la frontera sur de Córdoba, el 20 de febrero de 1792, contra el soldado Francisco Xavier Miranda, casado con María del Carmen Ferreyra en Pampayasta, ya que había iniciado algunos trámites para casarse con Florentina Aguirre. Miranda y la sumaria del caso fueron enviados a la comisaría de la Inquisición (aunque el proceso no se sustanció).

Asimismo, se encuentra una carta enviada por el Segundo Triunvirato en 1813, destinada al obispo de Córdoba Rodrigo Antonio de Orellana, en la que se transcribe el decreto de la Asamblea General Constituyente cuando declaró extinguida la Inquisición en todos los pueblos de las Provincias Unidas del Río de la Plata ${ }^{26}$. Así como el documento en el que Orellana manda que los vicarios pedáneos publiquen que el haber cesado el Tribunal de la Inquisición en las Provincias Unidas del Río de la Plata (por decreto del P. ejecutivo, fecha 24/III/1813) no eximía "de la estrecha obligación, penas y censuras, que la Iglesia tiene impuestas a todos los fieles para que denuncien o delaten a los herejes y a los sospechosos..." "pero deberán recurrir en la misma forma a los vicarios eclesiásticos de su feligresía, a quienes por el presente nombrados por tales Comisarios para celebrar y velar en la pureza de nuestra Sagrada religión..." ${ }^{27}$.

La colección dispone de un catálogo en soporte electrónico basado en el fichero cronológico en soporte papel que fue realizado en los años 40 y actualmente se encuentra en proceso de digitalización.

\section{A manera de conclusión}

La escritura de las "Inquisiciones periféricas", continúa siendo un desafío. Fuentes inexistentes, esquivas, que no hallamos en los archivos nacionales o centrales, nos obligan a pensar en los silencios y la ausencia de registros. Es entonces cuando buscamos posibles respuestas, tratando de ahondar en las redes que tejieron los comisarios con las autoridades locales o las obligaciones que debían cumplir siguiendo las órdenes de los superiores. De este modo, y munidos con nuevas preguntas y la ayuda de bibliotecarios y museólogos, hallamos nuevos documentos albergados en instituciones ligadas al poder de

26. Colección Monseñor Pablo Cabrera, FFyH-UNC. Inventario 12374, Año 1773; Inventario 12386, Año 1788; Inventario 09958 , Año 1792; Inventario 09114, Año 1813.

27. Colección Monseñor Pablo Cabrera, FFyH-UNC. Inventario 09165, Año 1813. 
la iglesia, la corporación académica e incluso de la monarquía. Documentos que nos ayudan a reconstruir la presencia y existencia del "control inquisitorial" que revistió distintos ropajes, en la periferia sur del imperio.

\section{TRANSCRIPCION DOCUMENTAL 28}

(Folio uno-Recto)

En la Ciudad de Cordova en veinte, y seis dias del Mes de septiembre de mil setecientos ochenta y nuebe Años El Señor Don Nicolas Perez del Viso Theniente de Governador Intendente con los Señores Alcaldes Ordinarios de primer y segundo voto Alguacil Mayor Don Antonio de las Heras Conseco, y Don Agustin de Igarzabal regidor defensor de pobres procedieron a la visita de Carzel en la forma, y manera siguiente

Primeramente Pedro de la Rosa del $1^{\circ}$ Voto aprovada latortura y siguiendose la causa de Orden de la Real Audiencia

Juan Josef Carrizo, y Geronimo Baquero de $2^{\circ}$ voto sindicados en muerte se paso a viso a su defensor para que pida publicacion de provanzas

Santiago Baldes, y Maria Luque de $2^{\circ}$ voto por muerte su causa testimoniandose para remitirla a Acesoria a Buenos Aires

Pasqual Monteros de $2^{\circ}$ voto por muerte su causa en plenario se pasò aviso asu defensor para que solicite la debolusión de las providencias que se libraron a su pedimento

Macario de $2^{\circ}$ voto Esclavo por muerte su causa en estado de haverse echo nombramiento de fiscal

Josef Ignacio Rodriguez de $1^{\circ}$ voto por muerte su causa enla Real Audiencia dela Plata Josef Luxan de $1^{\circ}$ voto sindicado en muerte su causa remitida al dictamen del Doctor Don Miguel Gaglimeana

Miguel Geronimo Moreno debuelta su causa de $1^{\circ}$ voto

28. Realizada siguiendo las normas de transcripción universalmente aceptadas. Biblioteca del Tribunal Superior de Justicia. Libro de Visita de Cárcel. Años 1789-1795. 
Juan Vizente Aguirre, y María Ochoa de $1^{\circ}$ voto por muerte su causa al dictamen del Doctor Carvallo aquien se le escribiò en el correo anterior

Lazaro Xigena de $1^{\circ}$ voto por muerte su causa remitida al parecer del Doctor Carballo Josef Cortes de $1^{\circ}$ voto por muerte su causa en estado de prueba

(Vuelta).

Margarita Montiel del $1^{\circ}$ voto por muerte su causa devuelta para practicar varias diligencias que pide el Abogado cuias ordenes se hallan libradas al efecto y acusado recibo Calisto Pereyra de $1^{\circ}$ voto por muerte su causa remitida al dictamen del Doctor Arias a quien se le escrivio

Manuel Quebedo del $1^{\circ}$ voto cumpliendo su destino en la Cadena por cinco años desde 27 de Febrero del corriente

Manuel Juncos del $1^{\circ}$ voto por muerte su causa sentenciada y remitida ala Real Audiencia del distrito

Juan de la Rosa Lucero del $1^{\circ}$ voto por robos y heridas su causa al dictamen del Doctor Carvallo, a quien se le escrivio carta para su despacho

Exmenegildo Rodriguez del $1^{\circ}$ voto por muerte su causa remitida al Abogado para que exponga su dictamen

Juan Ramires, Phelipe Santillan, y Josef Lino Peralta del $1^{\circ}$ voto por Ladrones y salteamientos y el segundo sindicado en muerte en estado de nombrarse fiscal

Luis Manuel de Menezes de $1^{\circ}$ voto por muerte su causa en grado de suplica en la Real Audiencia del distrito

Juan Antonio Gutierrez por estupro Juzgado del Señor Theniente su causa en contextacion

Miguel Indio pampa por el Señor Governador su causa en sumario

Francisco Molina, y Mercado por el Señor Governador, su Causa en contestazion

Thomas Reynoso de $2^{\circ}$ voto por robos de animales su causa en sumario se destino por quatro meses desta fecha ala Cadena

Atanacio Escudero de $2^{\circ}$ voto destinado por un año a la Cadena desde 22 de junio de este año Miguel Balencia destinado por diez años a la cadena que está cumpliendo 
(Folio 2-Recto).

Juan Reyna esclavo delos Rodriguez siga

Mariano Tulian Juzgado del Señor Theniente por muerte su causa en plenario librada providencia para el comparendo de un testigo, que falta que ratificarse

Francisco Surita, y Theodora Labayen del $1^{\circ}$ voto iniciados en la muerte de Don Manuel Gomez

Juan Josef Murua del $1^{\circ}$ voto por muerte su causa para remitirla con el reo a Catamarca en cuia Jurisdiccion la executo

Lasaro Aguirre Jusgado del Señor Theniente por muerte su causa en sumario

Francisco Borxa Basques del $1^{\circ}$ voto por insexto su causa en contextazion

Ramon Amarante, y María del Transito Baigorri de $1^{\circ}$ voto por muerte su causa en contextasion

Patricio Roca siga en la cadena

Domingo, y Francisco Salguero de $1^{\circ}$ voto por el tributo se encargo al Theniente de Alguacil Mayor los haga conchabar para que lo paguen

Ambrosio Reyna de $1^{\circ}$ voto por insexto su causa en constextasion

Lorenzo Molina de $2^{\circ}$ voto por varios excesos se ha reiterado nueba provdencia al comisionado Don Miguel Caldevilla para que siga sumaria por los nuebos delitos

conforme lo previene su Alteza

Mercedes Sarachaga por su ama siga

Cornelio Ruiz, Pedro Tinco, y Juan Asencio por el Señor Governador siguen en la cadena

Phelipe Bustos por el Señor Provisor

Mariano Brito por el Señor Comisario de Inquisisión

Bentura Guebara por el Sr. Theniente por muerte su causa en Plenario

Xavier Ignacio Amaya destinado ala Cadena por seis meses desde $1^{\circ}$ de Mayo de este año

Narciso Gonsalez Idem desde 22 de junio de este año por otro

Santos Mugas de $1^{\circ}$ voto por robos su causa en contextasion 
(Vuelta)

Mariano Oyola por muerte Juzgado del $1^{\circ}$ voto su causa en Sumario

Francisco Lorca destinado por ocho meses desde 22 de junio de este corriente año Juan Ignacio Galvan Juzgado del Sor Theniente por robos su causa en contextasion Josef Mathias Abeu por el Señor Governador por ratero, y bago siga

Luis Antonio Martines Juzgado del Señor Governador siga en la cadena Isavel Montenegro por el Señor Governador siga Jacinto Acosta destinado por un año ala Cadena desde 22 de junio del año corriente Julian Abreu destinado por ocho meses ala Cadena desde 22 de junio del año corriente Enrique Lopez Idem por un año desde 13 de Agosto del año corriente Eugenio Juarez del 1.voto por Ladron su causa en Sumario Julian Barrionuebo, Juan Francisco y Xavier Ochoa, y Francisco Solano Almonazi reos presos a disposision de las justicias dela Rioxa que los han remitido para custodiarlos de orden dela Real Audiencia del distrito

Josef Casas destinado a la Cadena por quatro meses desde 20 de julio del año que corre Bernabè Reyna por el Señor Theniente por heridas su causa en sumario Eusebio Allende de 2.voto por heridas su causa en sumario Roque Fredes por el Comisionado Don Dionisio Romero su causa en contextasion Juan Gregorio Riberos por el Señor Governador Pasqual Arguello por el Comisionado Don Cipriano Moyano su Causa en sumaria, y librada providencia para que baje el Sargento Mayor Don Santiago Ramallo a fin de que ponga acusación en forma

Francisco Villarreal destinado por dos meses ala Cadena desde el once de Agosto del corriente año 
(Folio 3-Recto).

Josef Gregorio Funes por el Señor Governador siga

Josef Sarmiento de $2^{\circ}$ voto por heridas su causa en sumario

Manuel Sanchez del 1.voto por ladron su causa en sumario se destino por seis meses ala Cadena desde esta fecha

Andres Cordova destinado por un año ala Cadena desde 21 de Agosto del corriente año

Pedro Juan Coronel Idem por dos meses

Pedro Josef Dias Idem por cuatro meses

Thomas Banegas del $1^{\circ}$ voto sindicado por ladron su causa en sumario

Bernardo Castro de $2^{\circ}$ voto por diferentes robos destinado por un año a la Cadena desde 22 de Agosto del año que corre

Pasqual Ruiz del $1^{\circ}$ voto sindicado en Robo siga

Pedro Ferreyra destinado por dos meses ala cadena desde 24 de Agosto

Manuel Vega Juzgado del Sor Theniente por iniciado en robos y resistencia a la justicia Josef Suarez de $1^{\circ}$ voto por iniciado en robos

Josef Lorenzo Ribera de $2^{\circ}$ voto por robo de animales que confiesa llanamente se destinó por un año ala Cadena desde esta fecha

Thomas Godoy Juzgado del Señor Governador iniciado por robos siga

Josef Maria Farias por el Señor Governador siga

Ilario Matos de 1. voto por deudas. Siga

Josef Ramon Quintero de 1.voto entretenido enla Cadena por ocho meses desde esta fecha

Juan Gregorio Dominguez de 1.voto siga entretenido en la cadena

Juan Alberto Murua de $1^{\circ}$ voto iniciado en robos siga entretenido en la Cadena Josef Santos Conzalez de $2^{\circ}$ voto indiciado en robos 
(Vuelta)

Justo Mayorano, Dionicio Diaz y Juan Cruz Leon, por el Señor Governador

Lorenzo Dias de $1^{\circ}$ voto, y esta a disposision del Señor Governador

Simon Aragon por el Señor Governador iniciado en robos de una muger, y algunos animales

Martin Lopez del $1^{\circ}$ voto iniciado en robos siga entretenido en la cadena

Pedro Medina y Agustin Villegas por el Señor Governador

Y dichos Señores aprovaron esta visita, que la firmaron por

ante mi el presente escribano de que doy feé

Perez del Viso- Gonzalez- Allende- Igarrzaval- Conseco

Ante mi

Martin de Arrascaeta

Escribano Público

y de Cabildo. 